Running head: controlling coaching and mental toughness

\title{
Controlling Coaching and Athlete Thriving in Elite Adolescent Netballers: The Buffering Effect of Athletes' Mental Toughness
}

\author{
Daniel F. Gucciardi ${ }^{1}$, Andreas Stamatis ${ }^{2}$, and Nikos Ntoumanis ${ }^{3}$ \\ ${ }^{1}$ School of Physiotherapy and Exercise Science, Curtin University \\ ${ }^{2}$ Department of Sport and Wellness, SUNY Plattsburgh \\ ${ }^{3}$ School of Psychology and Speech Pathology, Curtin University
}

Author Notes

*Address correspondence to Daniel Gucciardi, School of Physiotherapy and Exercise Science, Curtin University, GPO Box U1987, Western Australia, 6845. Phone: +61 89266 3653. Email: daniel.f.gucciardi@gmail.com. Daniel Gucciardi is supported by a Curtin Research Fellowship.

Manuscript accepted for publication in Journal of Science and Medicine in Sport (February $7^{\text {th }}$ 2017) 


\section{Abstract}

2 Objectives: The purposes of this study were to examine the association between controlling

3 coach behaviours and athlete experiences of thriving, and test the buffering effect of mental

4 toughness on this relation.

5 Design: A cross-sectional survey.

6 Methods: In total, 232 female netballers aged 11 to 17 years $(14.97 \pm 1.52)$ with between 1

7 and 15 years of experience in their sport $(7.50 \pm 2.28)$ completed measures of controlling

8 coach interpersonal style, mental toughness and thriving.

9 Results: Latent moderated structural models indicated that (i) controlling coach behaviours

10 were inversely related with experiences of vitality and learning; (ii) mental toughness was

11 positively associated with psychological experiences of both dimensions of thriving; and (iii)

12 mental toughness moderated the effect of coach's controlling interpersonal style on learning

13 but not vitality experiences, such that the effect was weaker for individuals who report higher

14 levels of mental toughness.

15 Conclusions: This study extends past work and theory to show that mental toughness may

16 enable athletes to counteract the potentially deleterious effect of controlling coach

17 interpersonal styles.

20 Keywords: interpersonal style of communication; latent interactions; mentally tough;

21 motivational climate; positive functioning; vitality; self-determination theory 


\section{Introduction}

In April 2013, the college sports world was shocked, confused and concerned by

24 videos that aired on ESPN's “Outside the Lines". Mike Rice, Rutger's head coach of the

men's basketball team, appeared to be adopting excessive personal control, repeated

intimidation and abuse towards players (verbally and physically) during practice. Rutgers

took corrective action against this extreme case of controlling coaching behaviour and fired

Rice as head coach. The attention subsequently turned to the victims, the players. However,

some student-athletes reported to have been less affected negatively by Rice's controlling

behaviour. In competitive and stressful sporting environments (e.g., college, professional,

31 Olympic), are there individual resources that play an important role in buffering the negative

effects of contextual stressors, such as controlling coaching interpersonal styles? In this

study, we examine the role of mental toughness as one such potential buffer.

Despite the proliferation of definitions and conceptualisations over the past decade, a

common theme amongst what seems like a fragmented and noncumulative literature is the

centrality of mental toughness for reducing the potentially deleterious effects of contextual

stressors for the enactment and maintenance of goal-directed pursuits[1]. This core theoretical tenet is captured in recent definitions in which mental toughness is conceptualised as "a

personal capacity to produce consistently high levels of subjective (e.g., goal progress) or

objective performance (e.g., sales, race time, GPA), despite everyday challenges and stressors as well as significant adversities" (p.28)[2]. As such, mental toughness is considered pertinent for major assaults (e.g., ACL injury) as well as acute (e.g., equipment malfunction) or chronic

(e.g., controlling coach) stressors that can impede human functioning ${ }^{1}$. Consistent with

\footnotetext{
${ }^{1}$ Resilience is often used interchangeably with mental toughness despite their conceptual differences, yet there are two key differences between these concepts ${ }^{2}$. First, resilience can apply to a broad array of systems (e.g., individuals, communities, economies), whereas mental toughness is confined to individuals. Second, resilience encompasses a range of protective factors including individual, social, and community resources. Mental toughness can be considered a resilience (personal) resource but does not capture the breadth and depth of protective factors of resilience.
} 
theoretical perspectives of stress[3], research has shown that mental toughness is positively associated with important indicators of human functioning (e.g., performance) because individuals high in mental toughness are less distressed and better able to cope with contextual demands[2]. An alternative yet largely untested perspective is that when individuals perceive a situation as stressful, the deleterious effects of stress may be less for individuals with high levels of mental toughness (i.e., buffering hypothesis). Researchers have examined the salience of mental toughness for functioning within a specific context (e.g., sport, workplace) solely in relation to life stress[4]. As such, there is a need for research that tests the buffering effects of mental toughness when the stressor and indicator of functioning are captured within the same context, sport, in the case of this paper.

In testing the buffering effect of mental toughness, we draw from recent work[5,6] where self-determination theory (SDT)[7] was employed as a guiding theoretical framework. Within the context of SDT, optimal human functioning can be fostered through the satisfaction of the psychological needs of autonomy (i.e., feelings of volition and selfendorsement), competence (i.e., feeling skilled and capable), and relatedness (i.e., feeling social valued and connected with others)[8]. Of central importance are social environments in which key agents in positions of authority (e.g., coaches) support or undermine these psychological needs through their interactions with others. Much work has focused on coach behaviours and interpersonal styles that satisfy these three needs (e.g., choice within boundaries, encouraging athlete input, provision of guidance and constructive feedback) because they predict a range of indices related to optimal functioning[9]. In recent years, however, researchers have devoted greater attention to understanding the motivational strategies and behaviours of social agents that may lead to needs frustration[10]. Referred to as a controlling motivational style, social agents can thwart the three psychological needs through the controlling use of rewards (i.e., extrinsic rewards and praise), conditional regard 
(i.e., withhold attention and support), intimidation (i.e., power assertive strategies to humiliate), and excessive personal control (i.e., intrusive monitoring and excessive or strict boundaries)[11]. Coach controlling motivational styles have been linked with a range of maladaptive outcomes including increased burnout[12] and stress[13]. These findings underscore the potentially stressful nature of controlling motivational styles within sporting contexts. However, to date, little work has focused on how the undermining effects of controlling environments can be buffered. Initial research suggests that mental toughness may serve to mitigate the maladaptive effects of controlling motivational styles[6], yet this hypothesis remains untested.

The concept of thriving is an important indicator of positive functioning that provides a conceptual thread between SDT and mental toughness[14]. Conceptualised as the opposite of languishing (e.g., stagnant, low positive affect), thriving is defined as a psychological state "marked both by a sense of learning (greater understanding and knowledge) and a sense of vitality (aliveness)" (p.537)[15]. Representing an internal gauge of cognitive and affective markers regarding how well one is doing [16], thriving fosters adaptive resource allocation, engagement with and commitment to tasks, proactivity, and performance[15,16]. With its centrality for goal-directed behaviour, mental toughness is a personal resource that should enable people to experience progress and growth[14] $]^{4}$. Longitudinal research with tertiary students supports the adaptive nature of mental toughness with regard to academic and social goal progress[2]. Similarly, meta-analytic data indicates that individuals are more likely to thrive when embedded in social contexts in which individuals feel volitional, capable and connected to others[17]. In contrast, when the three psychological needs are actively thwarted via controlling motivational contexts, individuals should be less likely to experience thriving. Research with male athletes[18] and a mixed-sex sample[19] revealed low and nonsignificant correlations between controlling coaching and vitality, whereas research with 
94 female athletes supported a salient inverse association[20]. Given these equivocal findings, additional research is required to test this theoretical expectation, and extend this past work to include both cognitive (learning) and affective (vitality) dimensions of thriving.

The purposes of this study were to examine the association between controlling coach behaviours and thriving, and test the buffering effect of mental toughness on this relation. In so doing, we proposed three hypotheses. First, mental toughness will be positively associated with psychological experiences of thriving. Second, controlling coach behaviours will be inversely related with psychological experiences of thriving. Third, athletes' mental toughness will moderate the inverse association between their coach's controlling interpersonal style and psychological experiences of thriving, such that this effect will be weaker for individuals who report higher levels of mental toughness. We tested these hypotheses on a relatively homogenous sample of elite adolescent netballers, who represent an understudied sport within the sport psychology literature.

\section{Methods}

In total, 232 female netballers aged 11 to 17 years $(14.97 \pm 1.52)$ took part in this study. Netballers had between 1 and 15 years of experience in the sport $(7.50 \pm 2.28)$ participating in between 1 and 10 hours of netball activities that were supervised by their coach (5.08 hours \pm 2.53$)$. Athletes who were involved in elite developmental squads throughout Australia and their parents were informed about the study via email. Athletes who expressed an interest were provided with a research package including an information sheet, consent form, multi-section survey, and a reply-paid envelope. Consenting athletes returned completed surveys directly to Netball Australia. We obtained approval from the relevant university ethics committee before participant recruitment. 
the multidimensional Controlling Coach Behaviours Scale[11], athletes reported their level of dis/agreement with 15 items considered reflective of four specific dimensions of coaches'

121 controlling interpersonal style: controlling use of rewards (e.g., "My coach only rewards/praises me to make me train harder"), negative conditional regard (e.g., "My coach pays me less attention if I have displeased him/her"), intimidation (e.g., "My coach threatens to punish me to keep me in line during training"), and excessive personal control (e.g., "My coach tries to control what I do during my free time”). Responses were recorded using a 7point scale $(1=$ strongly disagree to $7=$ strongly agree $)$. Consistent with recent research[13,21], we modelled coach interpersonal control as a higher-order construct for the

128 primary analyses. Using the unidimensional Mental Toughness Inventory[2], athletes rated

129 the extent to which 8 items were reflective of how they typically thought, felt and behaved as a netballer (e.g., "I strive for continued success" and "I am able to regulate my focus when performing tasks"). Responses were recorded using a 7-point scale $(1=$ false, $100 \%$ of the time to $7=$ true, $100 \%$ of the time). Using an adaptation of the multidimensional Thriving at

133 Work Scale[22], athletes reported the degree to which they experienced dimensions of

134 vitality (5 items, e.g., "At netball, I feel alive and vital”) and learning (5 items, e.g., “At netball, I find myself learning often") within the context of their netball pursuits. Responses were recorded using a 7 -point scale $(1=$ strongly disagree to $7=$ strongly agree $)$. For each scale, a total score was created by averaging participants' responses across those items

138 relevant to each construct. The research questions were tested using latent moderated structural (LMS) models,

140 which is considered superior to the traditional composite score approach because it produces

141 minimally biased estimates of moderation effects that are corrected for measurement

142 error[23]. We implemented a sequential 3-step analytical process where we tested the

143 adequacy of: (i) the measurement model of the latent constructs (Model 0), (ii) the structural 
144 model excluding latent interactions (Model 1), and (iii) the structural model including latent

145 interactions (Model 2)[24]. A visual display of Model 2 is provided in Figure 1. For Models 0

146 and 1, model-data fit was assessed using multiple indices and typical interpretation

147 guidelines, namely the $\chi^{2}$ goodness-of-fit index, comparative fit index (CFI), Tucker-Lewis

148 index (TLI), and root mean square error of approximation (RMSEA), with evidence of

149 adequate fit indicated by CFI/TLI $\geq .90$ and RMSEA $\leq .08[25]$. As there is no saturated

150 reference model, conventional model-data fit statistics cannot be applied to LMS models[26].

151 In the absence of such model fit indices, the log-likelihood ratio test $(D)$ can be used to

152 compare the relative fit of Models 1 and 2[23,24]. A composite reliability coefficient $(\omega)$ [27]

153 was calculated to estimate the level of internal reliability for each latent factor. We performed

154 all analyses within Mplus 7.4[28] using a robust maximum likelihood estimator (MLR) and

155 full information maximum likelihood (FIML) to ensure that all available data was used to

156 estimate model parameters. All Mplus output files and associated syntaxes are available in

157 the supplementary material.

\section{Results}

Descriptive statistics and bivariate correlations for all study variables are provided in

Table 1; full details at each stage of the analysis are provided in the supplementary material.

Models 0 and 1 represented an adequate fit with the data, $\chi^{2}(485)=771.37, p<.001, \mathrm{CFI}=$

$162.921, \mathrm{TLI}=.915, \mathrm{RMSEA}=.050(90 \% \mathrm{CI}=.044$ to .057$)$. In terms of composite reliability

163 estimates, mental toughness $(\omega=.85)$, coach controlling interpersonal style $(\omega=.95)$,

164 learning $(\omega=.84)$, and vitality $(\omega=.79)$ were deemed satisfactory. Using a $\chi^{2}$ distribution,

165 the log-likelihood ratio test, $D(2)=7.06, p<.05$, indicated that Model 1 resulted in a

166 significant loss in fit relative to Model 2. For the learning dimension of thriving, mental

167 toughness $(\mathrm{B}=.49,95 \% \mathrm{CI}=.32, .65)$, coach controlling interpersonal style $(\mathrm{B}=-.33,95 \%$

$168 \mathrm{CI}=-.50,-.16)$, and their interaction $(\mathrm{B}=.28,95 \% \mathrm{CI}=.01, .54)$ were salient determinants. 
169 As depicted in Figure 2 and established via simple slope analysis, the inverse effect of controlling coaching on experiences of learning was stronger when mental toughness was lower $(\mathrm{B}=-.54,95 \% \mathrm{CI}=-.88,-.20)$ but not when higher $(\mathrm{B}=-.12,95 \% \mathrm{CI}=-.28, .04)$. With regard to the vitality component of thriving, the effects of mental toughness $(\mathrm{B}=.64$, $95 \% \mathrm{CI}=.44, .85)$ and coach controlling interpersonal style $(\mathrm{B}=-.24,95 \% \mathrm{CI}=-.40,-.09)$ were significant, but not their interaction $(\mathrm{B}=.15,95 \% \mathrm{CI}=-.10, .40)$. The inverse association between mental toughness and coach controlling interpersonal style was small and statistically non-significant $(\mathrm{B}=-.11,95 \% \mathrm{CI}=-.22, .01)$. The inclusion of the latent interaction term accounted for additional $5 \%$ and $2 \%$ of the explained variance in learning (Model $1=41 \%$, Model $2=46 \%$ ) and vitality (Model $1=49 \%$, Model $2=51 \%$ ).

\section{Discussion}

Drawing from motivational theory[7,8], we examined controlling coach interpersonal styles as a contextually salient stressor within sporting contexts $[13,14]$ that may impede the degree to which athletes experience thriving, and the buffering effects of mental toughness.

183 Consistent with expectations, we found that (i) controlling coach behaviours were inversely related with experiences of vitality and learning; (ii) mental toughness was positively associated with psychological experiences of both dimensions of thriving; and (iii) mental toughness moderated the effect of coach's controlling interpersonal style on learning but not vitality experiences. controlling coach interpersonal styles[10]. Controlling coach behaviours have been associated with increased burnout via athlete perfectionism and motivational regulations[18], and psychological needs satisfaction and frustration[19]. In a three-wave, season long investigation of adolescent soccer players, controlling coach interpersonal style was associated with reductions in psychological need satisfaction and engagement[21]. Coach 
194 controlling style has been shown to be inversely associated with mental toughness via

195 psychological need frustration[6]. Our results add to this work to support a direct association

196 with thriving, such that athletes who experienced higher levels of controlling coach

197 behaviours reported fewer experiences of learning (cognitive) and vitality (affective). The

198 reasons why coaches might adopt controlling interpersonal styles are diverse and can be

199 broadly classified as pressures from above (e.g., organisational accountability and responsibility for performance outcomes of athletes and teams), below (e.g., athletes who are disengaged, disruptive, poorly motivated) and within (e.g., dispositional tendency towards controlling behaviours)[29].

Aligned with recent work[2,4,30], our findings provided additional support for the adaptive nature of mental toughness for positive functioning. We found moderate-to-large associations between mental toughness and psychological experiences of learning and vitality. These findings confirm past work that has demonstrated longitudinally the salience of mental toughness for thriving among university students over the course of a 12 -week teaching semester[2]. Collectively, our results and those of previous work provide accumulating evidence for the expectation that mental toughness provides an important foundation upon which to experience a sense of feeling energised and making progress

211 towards valued goals in achievement contexts[14].

213 may not influence all athletes equally. Specifically, we focused on mental toughness as an

214 individual difference variable that may alter the strength of the association between

215 controlling coach behaviours and important or valued outcomes. Past work has supported the 216 protective effects of mental toughness on life stress. In American college footballers, mental

217 toughness moderated the effect of positive life stress (but not negative life stress) on the 218 number of days missed due to injury, such that footballers with lower levels of mental 
toughness missed more days to injury when stress was high[4]. This work provided an important first look at the role of mental toughness on cross-contextual effects from life stress to an outcome variable specific to sporting contexts (i.e., injury). Extending this past work, we examined the salience of mental toughness when both the stressor and outcome are housed within the contextual boundaries of sport. Consistent with our expectation, the inverse association between controlling coach interpersonal style and experiences of thriving was stronger for athletes lower in mental toughness. However, mental toughness buffered the effect for the learning dimension of thriving only, that is, experiencing a sense of improvement and progress towards important and valued goals[15,16,22]. This finding corroborates the conceptualisation of mental toughness as a personal resource that reflects one's psychological capacity to behave successfully in goal-directed ways[2]. The centrality of mental toughness for self-actualisation (i.e., fulfilment of potential)[14] offers insight into this differential effect in that it provides direction towards self-referenced objectives, aligns behaviour with these goals, and fosters flexibility when faced with stressful or challenging contexts[2,14,30]. As such, mental toughness is a psychological resource that is more relevant for progress and development (the 'doing' part of thriving) than it is for positive emotions associated with those processes (the 'being' part of thriving).

As is the case with all research, this study is not without limitation. First, the crosssectional design does not permit inferences regarding temporal or causal associations; future research could adopt longitudinal or experimental approaches to provide stronger insight into the dynamic aspects of the relations among controlling interpersonal styles, mental toughness and thriving in sport. Second, our focus on adolescent female netballers limits the extent to which these findings may be considered representative of broader athlete populations; future research is required to ascertain the extent to which these findings can be replicated in other

243 sporting contexts, and extended via an understanding of the moderating effect of sex. 


\section{Conclusions}

This study corroborates previous findings regarding the maladaptive nature of

246 controlling interpersonal styles within achievement contexts, and provides one of the first

247 tests of how controlling environments can be buffered. In so doing, we extend past work and

248 theory to show that mental toughness may enable athletes to counteract the potentially

249 deleterious effect of controlling interpersonal styles. Additional research is required to

250 confirm our findings and extend understanding of the dynamic nature of the relations

251 between these personal and contextual factors.

\section{Practical Implications}

253 - The deleterious effects of controlling coach interpersonal styles on important or valued

254 outcomes such as thriving is less for those individuals with higher levels of mental toughness.

255 - Understanding why coaches employ controlling interpersonal behaviours is an important

256 first step to reducing the frequency with which such strategies are relied upon to motivate

257 athletes.

258 - There is a need to identify how athletes can sustain mental toughness when faced with

259 controlling interpersonal environments 
Controlling coaching and mental toughness 13

\section{Acknowledgements}

The lead author is supported by a Curtin Research Fellowship. 


\section{References}

1. Gucciardi DF, Hanton S. Mental toughness: Critical reflections and future considerations, Chapter 43, in Routledge International Handbook of Sport Psychology, New York, Routledge, 2016.

2. Gucciardi DF, Hanton S, Gordon S, et al. The concept of mental toughness: tests of dimensionality, nomological network, and traitness. J Pers 2015; 83(1):26-44.

3. Lazarus RS, Folkman S. Stress appraisal and coping, New York, Springer, 1984.

4. Petrie TA, Deiters J, Harmison RJ. Mental toughness, social support, and athletic identity: moderators of the life stress-injury relationship in collegiate football players. Sport Exerc Perform Psychol 2014; 3(1):13-27.

5. Mahoney JW, Ntoumanis N, Gucciardi DF, et al. Implementing an autonomysupportive intervention to develop mental toughness in adolescent rowers. J Appl Sport Psychol 2016;28(2):199-215.

6. Mahoney JW, Gucciardi DF, Ntoumanis N, et al. Mental toughness in sport: motivational antecedents and associations with performance and psychological health. J Sport Exerc Psych 2014;36(3):281-292.

7. Deci EL, Ryan RM. Intrinsic motivation and self-determination in human behaviour, New York, Plenum Press, 1985.

8. Deci EL, Ryan RM. The 'what' and 'why' of goal pursuits: Human needs and the self-determination of behavior. Psychol Inq 2000;11(4);227-268.

9. Ntoumanis N. A self-determination theory perspective on motivation in sport and physical education: current trends and possible future research directions, Chapter 3 , in Advances in motivation in sport and exercise: Volume 3, Ilinois, Human Kinetics, 2012.

10. Bartholomew KJ, Ntoumanis N, Thøgersen-Ntoumani C. A review of controlling motivational strategies from a self-determination theory perspective: Implications for sports coaches. Int Rev Sport Exercise Psychol 2009;2(2): 215-233.

11. Bartholomew KJ, Ntoumanis N, Thøgersen-Ntoumani C. The controlling interpersonal style in a coaching context: development and initial validation of a psychometric scale. J Sport Exerc Psych 2010;32(2):193-216.

12. Barcza-Renner K, Eklund RC, Morin A, et al. Controlling coaching behaviours and athlete burnout: investigating the mediating roles of perfectionism and motivation. $J$ Sport Exerc Psych 2016;38(1):30-44.

13. Taylor IM, Turner JE, Gleeson M, et al. Negative psychological experiences and saliva secretory immunoglobulin A in field hockey players. J Appl Sport Psychol 2015;27(1):67-78.

14. Mahoney J, Ntoumanis N, Mallett C, et al. The motivational antecedents of the development of mental toughness: a self-determination theory perspective. Int Rev Sport Exercise Psychol 2014;7(1):184-197.

15. Spreitzer G, Sutcliffe K, Dutton, J, et al. A socially embedded model of thriving at work. Organ Sci 2005;16(5):537-549.

16. Spreitzer GM, Porath, C. Self-determination as nutriment for thriving: building an integrative model of human growth at work, Chapter 15, in The Oxford handbook of work engagement, motivation, and self-determination theory, New York, Oxford, 2014.

17. Ng JYY, Ntoumanis N, Thøgersen-Ntoumani C, et al. Self-determination theory applied to health contexts: a meta-analysis. Perspect Psychol Sci 2012;7(4):325-340. 
18. Balaguer I, Gonzalez L, Fabra P, et al. Coaches' interpersonal style, basic psychological needs and the well- and ill-being of young soccer players: a longitudinal analysis. J Sports Sciences 2012; 30(15):1619-1629.

19. Felton L, Jowett S. "What do coaches do" and "how do they relate": their effects on athletes' psychological needs and functioning. Scand j Med Sci Sports 2013;23:e130e139.

20. Bartholomew KJ, Ntoumanis N, Ryan R, et al. Self-determination theory and diminished functioning: the role of interpersonal control and psychological need thwarting. Pers Soc Psychol B 2011;37(1):1459-1473.

21. Curran T, Hill AP, Ntoumanis N, et al. A three-wave longitudinal test of selfdetermination theory's mediation model of engagement and disaffection in youth sport. J Sport Exerc Psychol 2016;38(1):15-29.

22. Porath C, Spreitzer G, Gibson C., \& Garnett, F. G. (2012). Thriving at work: toward its measurement, construct validation, and theoretical refinement. J Organ Beh 2012;33(2):250-275.

23. Klein AG, Moosbrugger H. Maximum likelihood estimation of latent interaction effects with the LMS method. Psychometrika 2000;65(4):457- 474.

24. Maslowsky J, Jager J, Hemken. Estimating and interpreting latent variable interactions: a tutorial for applying the latent moderated structural equations method. Int J Behav Dev 2015;39(1):87-96.

25. Marsh HW, Hau KT, Grayson, D. Goodness of fit evaluation in structural equation modeling, Chapter 10, in Psychometrics. A Festschrift for Roderick P. McDonald, New Jersey, Erlbaum, 2005.

26. Jöreskog KG, Yang F. Nonlinear structural equation models: the Kenny-Judd model with interaction effects, Chapter 3, Advanced Structural Equation Modeling, New Jersey, Erlbaum, 1996.

27. McDonald RP. The theoretical foundations of principal factor analysis, canonical factor analysis and alpha factor analysis. Brit J Mat Stat Psy 1970;23(1):1-21.

28. Muthén, L. K., \& Muthén, B. Mplus users guide ( $7^{\text {th }}$ ed.). Los Angeles CA, Muthén \& Muthén, 2012.

29. Stebbings J, Taylor I, Spray C., et al. Antecedents of perceived coach interpersonal behaviors: the coaching environment and coach psychological well- and ill-being. $J$ Sport Exerc Psychol 2012;34(4):481-502.

30. Arthur CA, Fitzwater J, Hardy L, et al. Development and validation of a military training mental toughness inventory. Mil Psychol 2015;27(4): 232-241. 


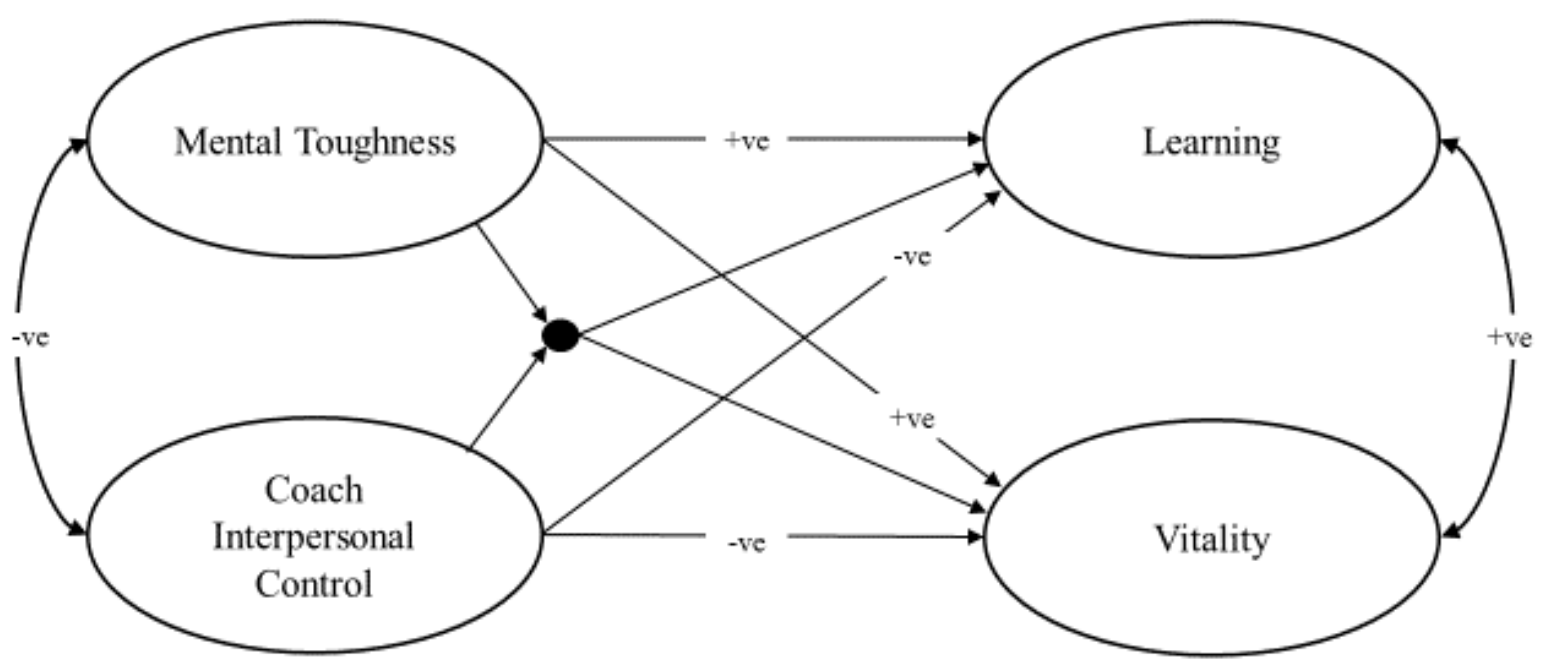

Figure 1. Diagrammatic representation of Model 2 including latent interaction between mental toughness and coach controlling interpersonal style (represented by a filled circle as per Mplus notation). Note: item indicators and residual variances are excluded for visual clarity; $+\mathrm{ve}=$ positive association expected; $-\mathrm{ve}=$ negative association expected. 


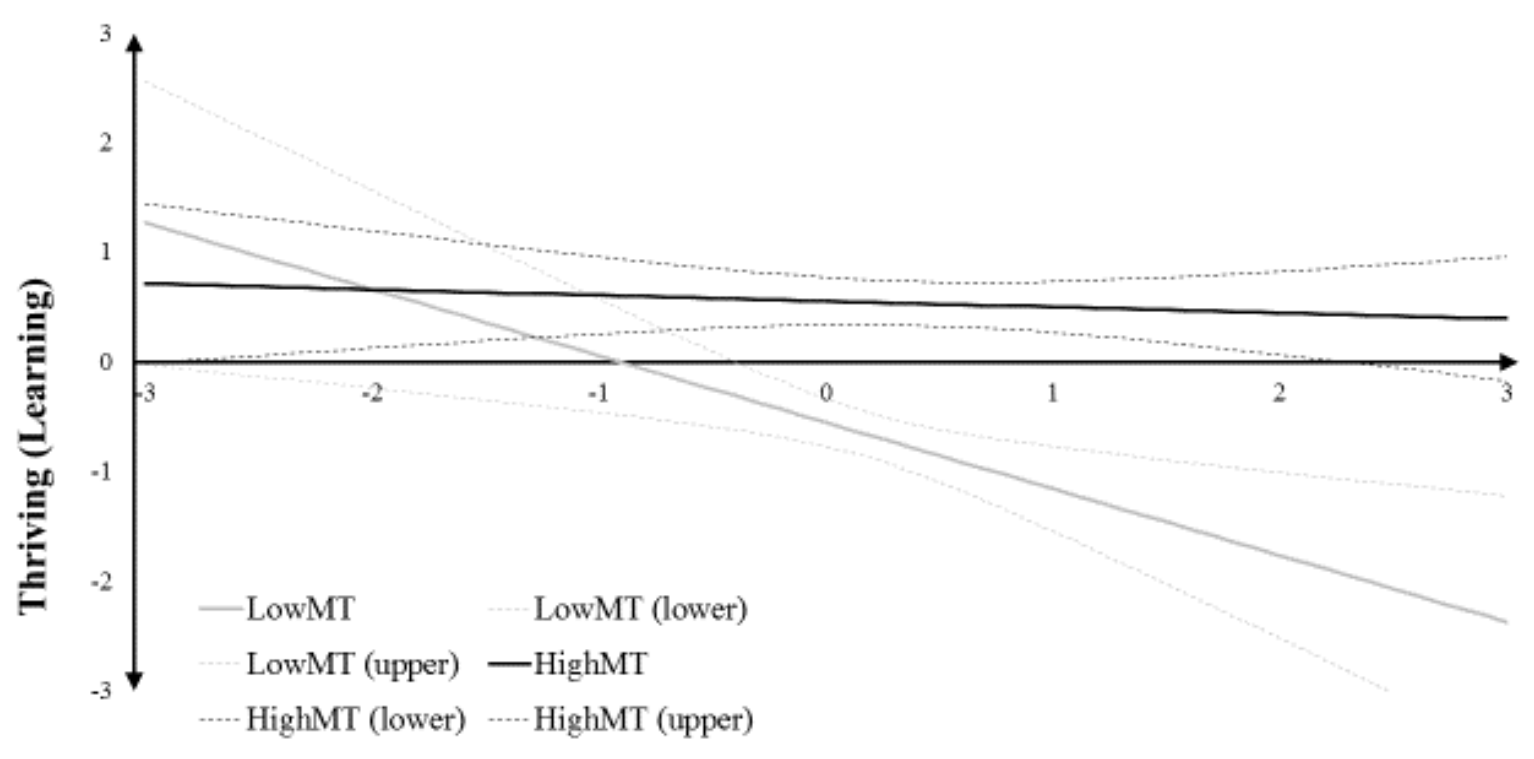

Controlling Coach Interpersonal Style

Figure 2. Latent interaction of mental toughness on the relation between controlling coach interpersonal style and learning dimension of thriving. Note: $95 \%$ confidence intervals around the slope are captured by "lower" [e.g., LowMT (lower)] and "higher" [e.g., LowMT (higher)] dotted lines. MT = mental toughness; LowMT = -1 standard deviation of the zero mean of mental toughness; HighMT $=+1$ standard deviation of the zero mean of mental toughness. 
Table 1. Descriptive statistics and bivariate correlations for study variables (Note: * $p<.05$, ** $p<.001$ ).

\begin{tabular}{|c|c|c|c|c|c|c|c|c|c|c|c|}
\hline & & 1 & 2 & 3 & 4 & Minimum & Maximum & $\mathrm{M}$ & SD & Skewness & Kurtosis \\
\hline 1 & Mental toughness & - & & & & 2.25 & 7 & 5.62 & .67 & -.84 & 2.39 \\
\hline 2 & Controlling coach & $-.14 *$ & - & & & 1 & 6.47 & 2.16 & 1.21 & 1.34 & 1.31 \\
\hline 3 & Learning & $.44 * *$ & $-.41 * *$ & - & & 2.60 & 7 & 6.10 & .81 & -1.18 & 1.67 \\
\hline 4 & Vitality & $.51 * *$ & $-.33 * *$ & $.69 * *$ & - & 2.80 & 7 & 5.83 & .83 & -.73 & .44 \\
\hline
\end{tabular}

